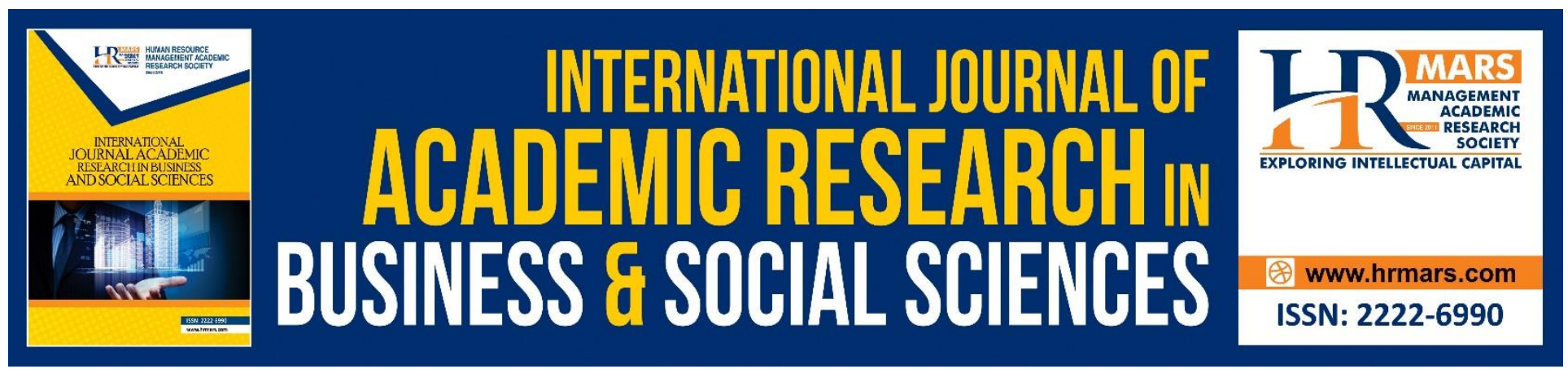

\title{
Knowledge Transfer Program: An Inclusive Conceptual Framework Model for Malaysia
}

Saidatulakmal Mohd, Siti Rahyla Rahmat, Mohamad Shaharudin Samsurijan \& Azlinda Azman

To Link this Article: http://dx.doi.org/10.6007/IJARBSS/v8-i11/4933

DOI: 10.6007/IJARBSS/v8-i11/4933

Received: 29 Sept 2018, Revised: 21 Oct 2018, Accepted: 11 Nov 2018

Published Online: 18 Nov 2018

In-Text Citation: (Mohd, Rahmat, Samsurijan, \& Azman, 2018)

To Cite this Article: Mohd, S., Rahmat, S. R., Samsurijan, M. S., \& Azman, A. (2018). Knowledge Transfer Program: An Inclusive Conceptual Framework Model for Malaysia. International Journal of Academic Research in Business and Social Sciences, 8(11), 598-606.

Copyright: (C) 2018 The Author(s)

Published by Human Resource Management Academic Research Society (www.hrmars.com)

This article is published under the Creative Commons Attribution (CC BY 4.0) license. Anyone may reproduce, distribute, translate and create derivative works of this article (for both commercial and non-commercial purposes), subject to full attribution to the original publication and authors. The full terms of this license may be seen

at: http://creativecommons.org/licences/by/4.0/legalcode

\section{Vol. 8, No. 11, 2018, Pg. 598 - 606}

Full Terms \& Conditions of access and use can be found at http://hrmars.com/index.php/pages/detail/publication-ethics 


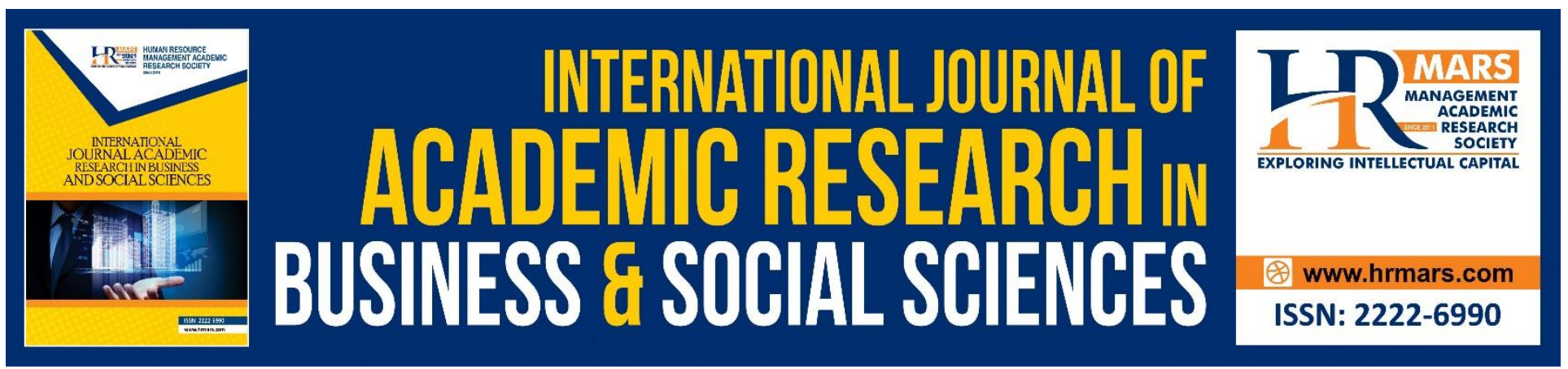

\title{
Knowledge Transfer Program: An Inclusive Conceptual Framework Model for Malaysia
}

\author{
Saidatulakmal Mohd, Siti Rahyla Rahmat, Mohamad Shaharudin \\ Samsurijan \& Azlinda Azman \\ School of Social Sciences, Universiti Sains Malaysia, 11800 Penang, Malaysia
}

\begin{abstract}
This study proposed a conceptual framework model for Knowledge Transfer Program (KTP) in Malaysia that is inclusive in nature. The current implementation of KTP in Malaysia lacks uniformity among Public Higher Education Institutions (IPTA), poor usage of resources and not comprehensive. Hence, there is a call for a structured and systematic national KTP framework. We first analyzed the different theoretical models (narrow concept, broader definition and integrative framework) to frame an inclusive conceptual framework KTP model for Malaysia. The framework was then presented to a group of researchers involved in KTP research in a Focus Group Discussion (FGD) to get feedback. The proposed conceptual framework model for KTP in Malaysia incorporates all elements of KTP broader definition. The model is inclusive that it includes all beneficiaries, key focus areas, measurable output and deliverable outcomes. The ultimate outcome of KTP is enhancement of quality of life for the people.
\end{abstract}

Keywords: Knowledge transfer program · Conceptual Framework Model ·Inclusive ·Malaysia $\cdot$ KTP

\section{Introduction}

It has been noted that knowledge for development started to gain global importance in late 1990s (Kim \& Tcha, 2012). To this end, as put forward by Lavis, Roberston, Woodside, McLeod \& Abelson (2003), 'knowledge transfer' has then emerged as a part of a process where research messages were somehow pushed by the producers of research to the users of research. Knowledge transfer is the process of mutually exchanging knowledge and creating new knowledge, which implies collaboration of individuals (Gagne, 2009) and exchanges of knowledge (Szulanski, 1996, 2000; Szulanski, Jensen \& Lee, 2003).

In promoting knowledge transfer there must exist a steady interaction among researchers, decisions makers and stakeholders, let them be community or industry. In fact, developed countries have already set some level of expectations to researchers (from public or private institutions) to engage in some form of knowledge transfer engagement (synonymously known as research transfer, technology exchanged, knowledge utilization, knowledge translation and knowledge exchange) 
(Jacobson, Butterill \& Goering, 2004). To facilitate knowledge transfer activities, several mechanisms such as joint researcher-decision maker workshop, inclusion of decision makers in research process, collaborative research (CHSRF, 1999) and interpersonal contact between researchers and decision makers [9] have been proposed. Depending on the aims and strategies of individual country, the implementation of knowledge transfer program (KTP) in individual country may differ, while maintaining the core principles of KTP. Regardless of which model is adopted, the goal of KTP is to increase the likelihood that research evidence will be used in policy and practice decisions to enable stakeholders to identify relevant policy and practice in addressing and pursuing national development agenda (Mitton, Adair, McKenzie, Patten \& Perry, 2007).

Quite often, researchers and decision makers do not really communicate with each other. Researchers often engage in research they thought are important, that may not be fundamental to the nation development. Policy makers, on the hand, rarely sees the importance of research prior to decision making process but repeatedly require the output or outcome of research to validate their policies or actions. However, both parties acknowledge that their activities are somehow driven by demand that may not be conducive for the success of KTP (Mitton et al., 2008). Researchers, for example, face challenges to ensure that their research fit real-world timelines, establish strong rapport with policy makers and justify activities that fit the traditional academic expectationperformance (CHSRF), 1999). Policy makers have limited knowledge on research process, shadowy understanding on academia, and perception on the unsuitability of undertaken research to the nations' needs (CHSRF,1999). The only way to break these challenges is to engage all parties in activities that promote the importance of each party's strength and synergize on each other's weaknesses.

Incidentally, it was announced that the KTP of Public Higher Education Institutions (IPTA) in Malaysia lacks the many dimensions as mentioned above, in addition to the non-comprehensive nature of its implementation (KTP Policy, 2011). There were also divergence of approaches and practices among IPTAs coupled with poor coordination and use of resources. As such, there is a need for a structured and systematic national KTP framework.

The present study proposes an inclusive conceptual framework model for KTP implementation in Malaysia. Specifically, the objectives of the study are as follow:

i. Review the different proposed theoretical models of KTP implementation, and

ii. Propose a comprehensive KTP framework model for Malaysia.

\section{Methodology}

Model Analysis: Three (3) models were adopted as basis and fundamentals to proposing a comprehensive conceptual model for KTP. The three theoretical models considered were:
i. Narrow concept
ii. Broader definition
iii. Integrative framework

Focus Group Discussion: One Focus Group Discussion (FGD) was conducted on $4-8^{\text {th }}$ January 2017 among researchers engaging in KTP projects. The FGD was conducted based on the World Café 
INTERNATIONAL JOURNAL OF ACADEMIC RESEARCH IN BUSINESS AND SOCIAL SCIENCES Vol. 8, No. 11, Nov, 2018, E-ISSN: 2222-6990 @ 2018 HRMARS

concept. There were five (5) groups who had evaluated the conceptual model and provided their inputs for the betterment of the model.

Content Analysis: Content analysis of the current KTP Implementation Model of Malaysia was done to compare against the available theoretical models. Rigorous partition of the model was done to strengthen the current implementation model.

\section{Analysis and Discussion \\ Comparison of Different KTP Models}

A narrow concept of knowledge transfer model is a collaboration of three main players (researchers, decisions makers and stakeholders). Knowledge transfer will fail without strong and sincere collaboration and cooperation of the key players (Goh \& Richards, 1997). A successful knowledge transfer model must move away from the above narrow concept and embrace a broader definition in which knowledge transfer embraces all functions that could lead to an improved use of knowledge output for the benefit of society and its individuals. Following the suggestion from the European Commission's Expert Group (Finne, Day, Piccaluga, Spithoven, Walter \& Wellen, 2011) knowledge transfer model needs to have three distinct types of activities that involve research activities, knowledge activities and economic activities. The outputs of the research comprise not only new knowledge but also more knowledgeable researchers, to continue the knowledge transfer process. The European Commission's Expert Group (Finne et al., 2011) further emphasizes on the need to consider intertwining knowledge transfer activities and processes from research sector to economic sector under four perspectives that include:

(i) Networks where knowledge travels;

(ii) Transfer of knowledgeable people;

(iii) Institutional cooperation in solving problems and opening opportunities; and

(iv) IP management to facilitate exploitation of research results.

Given the complexity of managing knowledge transfer, (Goh, 2002) stresses on the importance of taking a more balance approach to the process. She suggests an integrative framework towards a successful knowledge transfer management in organisational settings that could conveniently be replicated in any settings. This integrative framework includes the 'soft' factors of knowledge transfer that are often abandoned by many organizations but important elements to influencing effective knowledge transfer. The five elements are leadership, problem-solving / seeking behavior, support structure, absorptive and retentive capacity and types of knowledge.

The key element is leaders who have a major influence in an organisational structure and to promote knowledge sharing. Not only that leaders need to show willingness to share information and knowledge they must also convey positive attitudes that knowledge is a mechanism to problem solving and effective organisation. The next element is to inculcate the culture of problem seeking and problem solving for continuous improvement and learning. Another vital element is the availability of support structure that could be divided into four sub elements that are technology, training and skill development, rewards and organizational design. The fourth element that is absorptive and retentive capacity refers to the ability of the parties involved to have the basic and 
INTERNATIONAL JOURNAL OF ACADEMIC RESEARCH IN BUSINESS AND SOCIAL SCIENCES

Vol. 8, No. 11, Nov, 2018, E-ISSN: 2222-6990 @ 2018 HRMARS

necessary knowledge to learn and understand each other for effective communication. The final element that is types of knowledge transferred needs to be matched with the intended processes.

\section{Evaluation of KTP Framework for Malaysia}

KTP implementation in Malaysia lies on the strategic partnership and shared responsibilities of three main stakeholders: academia, industry, community and graduate or postgraduate intern (Figure 1). According to KTP Policy Paper (Mitton et al., 2007) academia should be able to incorporate relevant and up to date knowledge from industry and community into their teaching, learning, research and consultancy activities, while industry and community are expected to utilise IPTAs resources for their benefits to enhance their business capability, economic activities and quality of life. Throughout the entire process, graduate interns are expected to enhance their personal and professional development. All in all, there should exist mutual benefits between all stakeholders involved in any KTP activities.

At present, it could be concluded that the KTP model of implementation for Malaysia follows the narrow concept definition of KTP with little elaboration on the components. Academia represents researchers while community / industry represents stakeholders. Decisions makers do not enter the model of KTP implementation as the projects approved under KTP should follow the classifications of national Key Results Areas (KRA) and National Priority Areas (NPA) set by the government. Five (5) KRAs were economy, education, green technology, disadvantaged group and relevant curriculum. Beginning of 2015, KRA was replaced with nine (9) focused areas: water security, energy security, transportation and urbanisation, biodiversity, cyber security, environment and climate change, food security, medical and healthcare and plantation crops and commodities.

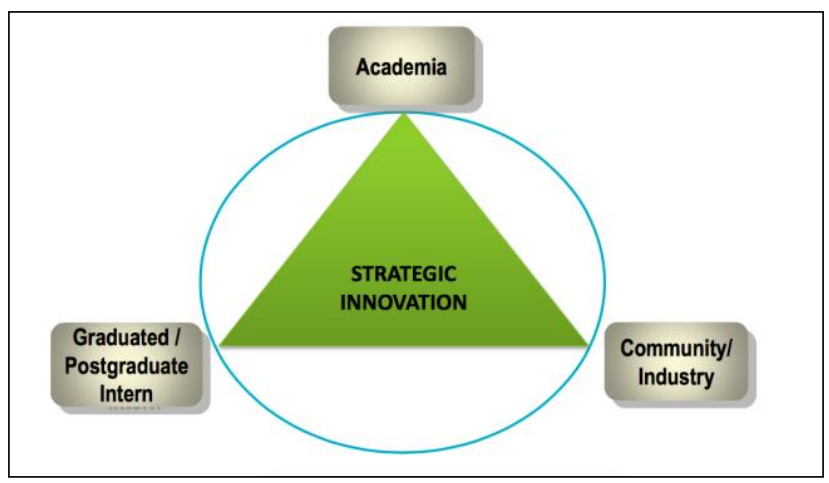

Figure 1: Model of KTP implementation in Malaysia [11]

To take into accounts of the broader definition of KTP model, KTP model framework for Malaysia should distinctively outline their activities as follows

i. Research activities (RA): Publication, Patent, Consultation and Joint Research.

ii. Knowledge activities (KA): Study tours, Training, Teaching and Meeting.

iii. Economic activities (EA): Process, Material, Skills and Innovation.

All the activities would be used as an assessment for the output generated or produced by any KTP projects. Under KTP Policy (2011), there was no clear definition on the outputs from KTP projects. 
While KTP Policy (2011) briefly included samples of impact measurement of KTP, it was mentioned in the document that impact measurements are to be approved by KTP Project Committee. Hence, impacts could vastly differ based on projects and evaluators. An example of impact for education was percentage (\%) improvement in public examination while example impact for disadvantaged groups was percentage (\%) increase in annual income for target groups. It is important to take into account that progress in quality of life is not necessarily measurable based on monetary and non-monetary tangible measurements. We need to take into account of the 'soft' factors as mentioned by Goh (2002).

\section{Proposed KTP Conceptual Framework Model}

As commonly stipulated, every country has the privilege to choose procedures and practices that are best designed for their countries, the most effective in their context with academia part of the process. Policy-makers had been very concern on how to ensure that the knowledge generated among academia can be transferred to industry so that community and local businesses will be benefit through it (WIPO, 2007). It is also vital to align KTP outcome with measurable value of knowledge to the society to ensure mutual benefits. Alimohammadlou and Eslamloo (2016) indicated that knowledge transfer activities between industry and universities have brought a positive impact on both sides. Hence, it is proposed that sets of outcomes to represent the 'soft' factors are incorporated in the comprehensive conceptual framework model. The tangible outcomes are classified as new services, new products, more work opportunities, advanced technology, innovative materials and speedy process. Given that intangible outcomes are difficult to measure only one outcome that is dissemination of knowledge is considered. There is a need to ensure that any knowledge transfer needs to translate into action such as policy implementation upon understanding the problems such knowledge transfer is addressing (Ward, Smith, House \& Hamer, 2012).

The proposed KTP inclusive conceptual framework model for Malaysia incorporates all the elements of the KTP broader definition (Figure 2) and suggestions put forward during the FGD. Four important comments received during the FGD in the development of the conceptual framework model were:

i. to include 'strategy and action plan' into the conceptual framework model,

ii. to include 'Non-Profit Organizations, marginalized groups and disadvantaged groups' as part of community,

iii. to add profit and compliance to standard in Output, and

iv. to add impact into the conceptual framework model. Among the suggested impacts were new industries, lower healthcare cost, improved quality of life and job creations. 
INTERNATIONAL JOURNAL OF ACADEMIC RESEARCH IN BUSINESS AND SOCIAL SCIENCES Vol. 8, No. 11, Nov, 2018, E-ISSN: 2222-6990 @ 2018 HRMARS

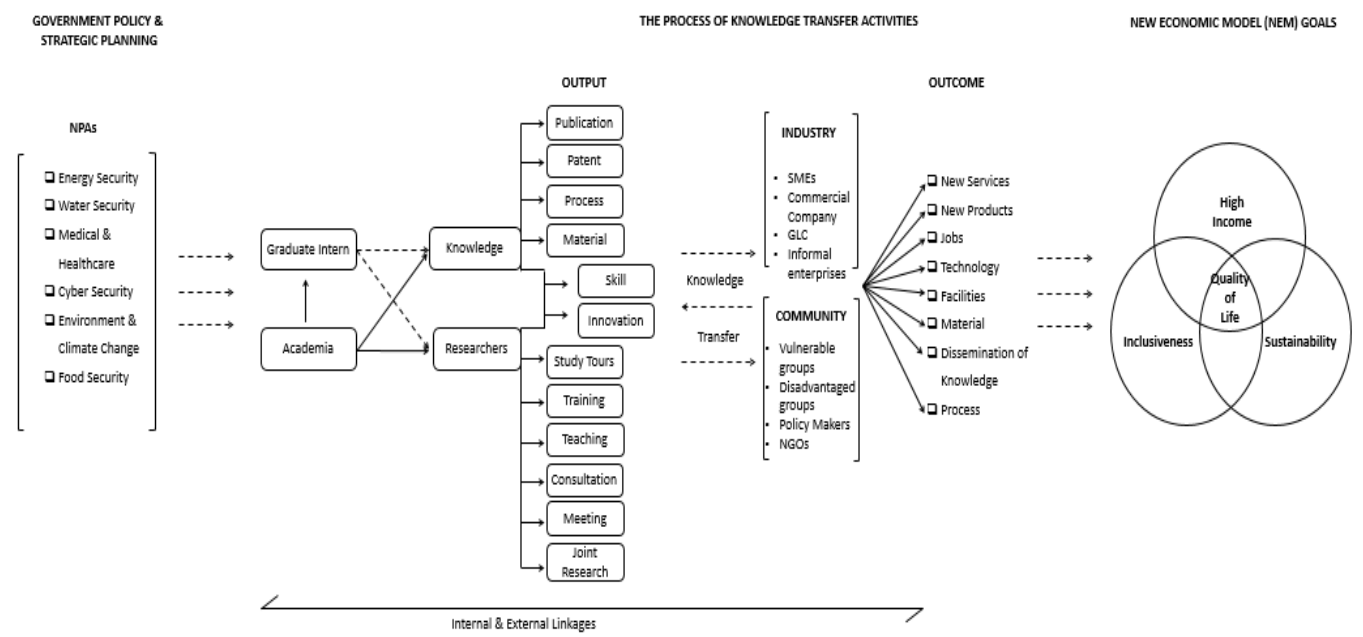

Figure 2: Inclusive conceptual framework model of KTP in Malaysia

The proposed KTP model should be developed based on fulfilling and accomplishing the goals of the New Economic Model (NEM) to enhance the wellbeing of the people through three great efforts of high income, sustainability and inclusiveness. NEM was introduced in 2010 and aims for Malaysia to be a high-income nation. As could be deduced from Figure 2, all outcomes of KTP are shown to direct to NEM, an indicator that the outcomes are in line with NEM. The three circles of NEM could be achieved through great linkages between the members of the country and international linkages of external organization. It is perhaps worthwhile to conduct forums, discussion and networks beyond own country to have a better understanding of knowledge sharing. This step was adopted by Korea (Lim, 2015) through its general infrastructure of knowledge exchange. Successful technology transfer requires good connections with the region's business, industry and financial community as well as public bodies (Mainen \& Sinervo, 2015).

All the four comments were included in the proposed model where NPAs (the most left) serve as the foundation and basis for developing and awarding KTP projects. Beneficiaries of the KTP are divided into two groups: industry and community. Industry included Small Medium Enterprises (SMEs), commercial companies, Government Link Companies (GLC) and informal enterprises. Community included vulnerable groups, disadvantaged groups, policy makers and non-governmental organizations. Figure 2 indicates that knowledge transfer is a two-way interaction between that benefit industry, community, academia and policy makers. Following the broader definition of KTP, the outcome from KTP projects need to be measured based on certain benchmarks that are both tangible and non-tangible measures as demonstrated in Figure 2.

The inclusiveness of the proposed model is measured based on four elements that are beneficiaries, key focus areas, measurable output and deliverable outcomes. As explained beneficiaries include all groups that cover industries and communities. Key focus areas follow the nine (9) national priorities areas. Measurable output and outcomes are the expected results from any KTP projects (Figure 2). 
INTERNATIONAL JOURNAL OF ACADEMIC RESEARCH IN BUSINESS AND SOCIAL SCIENCES Vol. 8, No. 11, Nov, 2018, E-ISSN: 2222-6990 @ 2018 HRMARS

\section{Conclusion}

Given the three available theoretical models of KTP (narrow concept, broader definition and an integrative framework of knowledge transfer model) it has been concluded that the existing KTP model for Malaysia follows the narrow concept of KTP. We acknowledged that while KTP model in Malaysia is simple, its implementation is holistic that it covers all macroeconomic areas that are essential in the nations. The areas addressed include economy, education, green technology, industry relevant curriculum, disadvantage group, water security, energy security, transportation and urbanization, biodiversity, cyber security, environment and climate change, food security, medical and healthcare and plantation crops and commodities

This paper has proposed an inclusive KTP conceptual framework model for Malaysia to incorporate the broader definitions and integrative framework of KTP. The model is inclusive that with regard to beneficiaries, key focus areas, measurable output and deliverable outcomes. The proposed new model emphasizes on the needs to align KTP model with the objectives of the NEM. To check on this, the outcome of the projects from KTP need to be measured based on a benchmark that could be followed and materialized for a larger population. This model is far from perfect, with many flaws, but this is a start to a comprehensive and inclusive KTP model in Malaysia.

\section{Acknowledgement}

Authors acknowledge the financial support from Ministry of Higher Education and Knowledge Transfer Programme (KTP) Secretariat for funding received under the KTP Research Programme titled 'Establishing a KTP Programmatic Framework for Project Engagement and Integration with National Level Policies and Concepts' (project code: K-KTP/05(USM-15).

\section{Corresponding Author}

Saidatulakmal Mohd, Associate Professor (Economics), School of Social Sciences, Universiti Sains Malaysia, 11800 Penang, Malaysia.

\section{References}

Alimohammadlou, M., \& Eslamloo, F. (2016). Relationship between total quality management knowledge transfer and knowledge diffusion in the academic settings. Procedia-Social and Behavioral Sciences, 230, 104-111. doi:10.1016/i.sbspro.2016.09.013

Canadian Health Services Research Foundation (CHSRF). (1999). Issues in linkage and exchange between researchers and decision-makers: Summary of workshop convened by CHSRF.

Finne, H., Day, A., Piccaluga, A., Spithoven, A., Walter, P., \& Wellen, D. (2011). A composite indicator for knowledge transfer. Report from the European Commission's Expert Group on Knowledge Transfer Indicators.

Gagne, M. (2009). A model of knowledge-sharing motivation. Special Issue: Human Resource Management, 48(4), 571-589.

Goh, S. C. (2002). Managing effective knowledge transfer: An integrative framework and some practice implications. Journal of Knowledge Management, 6(1), 23-30.

Goh, S., \& Richards, G. (1997). Benchmarking the learning capability of organizations. European Management Journal, 15(5), 575-583. 
INTERNATIONAL JOURNAL OF ACADEMIC RESEARCH IN BUSINESS AND SOCIAL SCIENCES

Vol. 8, No. 11, Nov, 2018, E-ISSN: 2222-6990 (C) 2018 HRMARS

Jacobson, N., Butterill, D., \& Goering, P. (2004). Organizational factors that influence university-based researchers' engagement in knowledge transfer activities. Science Communication, 25(3), 246259.

Kim, Y., \& Tcha, M. (2012). Introduction to the knowledge sharing program (KSP) of Korea. Washington, U.S: Korea Economic Institute.

KTP Policy. (2011). Knowledge Transfer Programme (KTP).

Lavis, J. N., Robertson, D., Woodside, J. M., McLeod, C. B., \& Abelson, J. (2003). How can research organizations more effectively transfer research knowledge to decision makers? The Milbank quarterly, 81(2), 221-248. doi:10.1111/1468-0009.t01-1-00052

Lim, W. H. (2015). Korea's knowledge sharing program (KSP). Joint US-Korea Academic Studies.

Malinen, P., \& Sinervo, P. (2015). Knowledge transfer in selected European universities. European Scientific Journal, 11(10).

Mitton, C., Adair, C. E., McKenzie, E., Patten, S. B., \& Perry, B. W. (2007). Knowledge transfer and exchange: review and synthesis of the literature. Milbank Quarterly, 85(4), 729-768.

Szulanski, G. (1996). Exploring internal stickiness: Impediments to the transfer of best practice within firm. Special Issue: Knowledge and the Firm, 27-43.

Szulanski, G. (2000). The process of knowledge transfer: A diachronic analysis of stickiness. Organizational Behavior and Human Decisions Processes, 82(1), 9-27.

Szulanski, G., Jensen, R.J \& Lee, Tanya (2003). Adaptation of know-how for cross border transfer. Management International Review, Special Issue 2003/3, 131-150.

Thompson, G. N., Estabrooks, C. A., \& Degner, L. F. (2006). Clarifying the concepts in knowledge transfer: a literature review. Journal of Advanced Nursing, 53(6), 691-701.

Ward, V., Smith, S., House, A. \& Hamer, S. (2012). Exploring knowledge exchange: A useful framework for framework and policy. Social science \& medicine, 74(3), 297-304.

World Intellectual Property Organization. (2007). Technology transfer, intellectual property and effective university-industry partnership. WIPO. 